\title{
Some Thoughts on How to Embody Chinese Culture in Chinese National Folk Dance Teaching
}

\author{
Hui Dong \\ Hubei Engineering University, Xiaogan Hubei, 432000, China
}

Keywords: National folk dance, Chinese culture, Teaching practice.

\begin{abstract}
The Chinese national folk dance is a rather common course provided by art colleges at all levels. The national folk music dance art teaching not only imparts corresponding dance art knowledge to students but also trains students' dance skills, imparts excellent national traditional classic culture to students and plays an extremely important role in inheriting excellent national culture, so art colleges pay high attention to it. This paper starts from Chinese traditional culture and analyzes the measures to embody Chinese culture in Chinese national folk dance teaching, in the hope of providing good support for the inheritance of Chinese culture in Chinese national folk dance teaching.
\end{abstract}

\section{Introduction}

As a time-honored country with an ancient civilization, Chinese boasts its deep cultural deposits and the rich multi-ethnic cultures formed in the long development course of Chinese nation, extremely impacting the inheritance and development of Chinese traditional culture. The dance art has its particularly favorable development advantages in China's atmosphere of thick Chinese culture. The dance arts of different nationalities collide with each other, join together and integrate with each other in their development processes to jointly make up the rich national cultural art. Therefore, it is extremely necessary to embody and inherit Chinese national culture in national folk dance teaching at all levels; namely, integrate Chinese culture into the national folk dance art teaching, enriches the artistic connotation of national folk dance, promote the well inheritance of Chinese national culture and lay a solid foundation for the sustainable and stable development of Chinese national folk dance.

\section{The long-standing and well-established Chinese traditional national culture}

Affected by the cultural difference between the east and the west, there are some differences in interpreting Chinese national folk dance between the east and west cultural systems. Besides, scholars of all countries in the world have studied and explored the national folk dance. Through ceaseless analysis and demonstration, they have made the corresponding conclusion that the dance forms have been developed accordingly through historical processing for a long time and are inherited from generation to generation after continuous selections and eliminations. Chinese scholars, who have also properly studied the national folk dance, think that the Chinese national folk dance is a widespread traditional dance form, which can show some national styles and local characteristics. Also, some scholars hold different views on the connotation of national folk dance and think that the national folk dance is a form of dance art collectively created and formed through continuous accumulation by the laboring people after long-term production and living, so it is popular with the masses. Researchers also think that culture is an important mark for the continuous development of human society. Especially for China, a multiethnic country, national folk dances were formed by different nationalities in the continuous development process, so different dance cultures are rich in cultural deposits. With a development history of 5000 years, Chinese nation has formed rich and 
long-standing cultural forms during its development, including rich national dance culture elements. The national folk dance is also manifested in various ways and is one of the earliest artistic classes in world dance art. From this analysis, it can be seen that the national folk dance is the artistic achievement created by humans during their participation in social laboring life, is an artistic form generated gradually based on human's psychological and physical needs, and is closely related to the development history of human society. Therefore, different nationalities have formed their rich national cultural forms in the development process, so the national dances of all nationalities have their unique styles and ways of emotional expression and are affected by the national traditional cultures.

\section{Specific performance of Chinese culture in national folk dances}

\section{Show Chinese culture in classroom teaching of technical movement of national folk dances}

Integrating Chinese culture into the classroom teaching of national folk dances and specifically showing it in dance teaching practice are important ways to inherit Chinese culture in dance teaching. Specifically, it is required to proceed with teaching content teaching manifestation patterns to embody Chinese culture in national folk dance teaching practice.

Firstly, show Chinese culture in the national folk dance teaching content. As China is a multiethnic country, Chinese national folk dances are relatively widely distributed, have a great variety, have formed different dance styles, manifest the different characteristics of national culture and show the inheritance of typical types of national culture. In the national folk dance teaching practice, teachers should particularly emphasize the vocabulary which can reflect the typical national mentality and types, highlight the style and rhythm of dance art which can show people's spirit of a nationality, try to decompose such elements into the most basic elements of national folk dance art teaching and provide intensive training for students in order to guarantee the inheritance of Chinese culture [1]. Through the teaching and training concerning dance culture, students can correctly grasp the style characteristics, cultural connotations and kinetic potential principles of different national folk dances and can have their ability to apply body language improved. In addition, after learning for a long time, students can comprehend the artistic thoughts of folk dances of different styles in combination with the customs and cultures in different areas, grasp the ability and skills for creation of dance art, improve their learning effect of national folk dance art and enhance the ability to master national culture.

For example, when students are learning the national dance of the Korean nationality, the teacher should firstly introduce the development history of Korean dance to students first in teaching practice; namely, the Korean dance, which was formed by the Korean nationality under the edification of nature and through the continuous communication and integration with other nationalities, is characterized by the deep upholding of white, respecting the aged, loving cleaning and emphasizing understanding etc. In the traditional culture of the Korean nationality, a crane is regarded as the symbol of happiness and longevity, so the crane has a far-reaching influence in the Korean culture and the formation of Korean dance was closely related to the crane culture. We can even say that the Korean dance is Korean people's artistic sublimations of upholding the red-crowned crane mentality and psychology. Based on this, in order to help students to systematically understand Korean dance while teaching the technical movements of Korean dance, a teacher should make students to fully understand the artistic conception shown by the shape and image of a red-crowned crane as well as the dancing posture of a red-crowned crane by means of multimedia teaching in teaching practice, master the elegant and graceful artistic style of Korean dance and show the connotation of Korean culture in the Korean dance performance. Take "crane foot movement", a basic foot movement which can mostly embody the artistic style of Korean folk dance, for example. During the intensive training of the dance foot movement, students should master the breathing rhythm and skills during foot movement training, pay attention to the "pause", "connotation" and "bouncing" among the technical movements of the dance, consider "breathing" and "flexion and extension" as key teaching points and 
thus can perfectly show the artistic style characteristics of Korean dance. In this way, reasonably integrating Chinese culture into the process of selecting teaching content can further expand students' scope of knowledge, significantly improve students' ability to understand, master and show dance movements, help students to deeply master the formation of personality and psychology of people of a specific nationality in their actual performance process, enhance students' dance technique level and has some positive impacts on the inheritance of Chinese culture and the development of national culture.

Secondly, permeate Chinese culture in the selection and making of national dance costumes. To highlight the national and regional characteristics when making and selecting dance costumes in the field of dance art creation, some national culture connotations are usually integrated into the making and selection of dance costumes so as to form specific cultural tastes for national dance costumes and manifest the different cultural art characteristics [2]. Based on this, in the national folk dance teaching practice, teachers should formulate corresponding teaching strategies based on the actual conditions, possibly try to use vivid and visual demonstration contents when selecting the contents of dance costumes, and let students to learn the costumes and dance props of different national styles so as to fully arouse students' imagination and association, help students to participate in intensive training at scenes with national dance connotation and cultural atmosphere, and effectively improve the teaching effect.

For instance, when teaching the Dai national dance, teachers should let students to learn that the Dai people live in Yunnan area, which has long been known as "the kingdom of animals and plants". Affected by the local geographical environment, most Dai national costumes show the characteristic of elegance and women usually wear close-fitting barrel skirts. When they are engaged in agricultural production labor, a picturesque scene can be shown on the background of the natural magnificent rivers and mountains. Then, teachers can choose costumes with the thick Dai style, organize students to conduct intensive training of Dai dance, and create a specific artistic conception of Dai national culture for students so that students can complete the learning and training of Dai dance at a specific scene, can deeply understand Dai dance and show the cultural charm of the nationality in all their gestures and expressions. Meanwhile, in order to really integrate Chinese culture into Chinese folk dance teaching practice, teachers can also use national traditional costumes as auxiliary teaching materials to jointly analyze and discuss the national culture elements contained in different national costumes and the national culture connotations manifested in different parts of national costumes together with students so that students can systematically understand national culture and thus deeply understand national dances [3]. Showing Chinese culture in dance and costume teaching in this way can enrich the cultural connotations of national folk dance teaching, help to further inherit Chinese culture and have some positive influences on the favorable development of Chinese culture.

\section{Show Chinese culture in the course teaching of appreciation and analysis of dance dramas}

The course of appreciation and analysis of dance dramas is also an important part. The good implementation of the course of appreciation and analysis of dance dramas has certain positive impacts on training students' comprehensive quality and enhance students' aesthetic ability. For this reason, to show Chinese culture well in national folk dance teaching, try to integrate Chinese culture into the course teaching of appreciation and analysis of dance dramas, highlight the artistic value of Chinese culture and help Chinese culture to gain more extensive acceptation. For instance, the Mountains Rivers Show, a large dance with national costumes and national style, is a rather typical dance drama, which contains rich artistic techniques of expression, organically combines modern dance art with the traditional dance art and highlights the specific cultural value [4]. In the course of appreciation and analysis of dance dramas, teachers can use the dance drama as a teaching drama and explain its rich cultural contents in the process of drama appreciation and analysis, such as the life style and customs, cultural legends and festival customs of the eight nationalities, so that students can preliminarily learn the national cultures of the eight nationalities. Later, teachers can systematically analyze the dances of the eight nationalities from the perspective of dance art, help students to 
comprehensively learn the watery softness, beauty and cheerfulness of Dai dance, the originality and plainness of Huasu dance and humor of Mosuo dance, make students to grasp the cultural connotations in the dance drama, give students a good impression and lay a solid foundation for students to deeply learn national culture. Basically all national folk dance dramas contain rich thoughts of Chinese culture, so teachers can help for the favorable inheritance of Chinese culture accordingly if they intentionally highlight the Chinese culture in the teaching practice of appreciation and practice course.

\section{Integrate Chinese culture in the national folk dance performance}

The performance of Chinese culture in national folk dances is also shown in the actual performance process of dance works. When giving a performance of dance works, dancers deeply understand the artistic connotation of dance and the cultural thought contained in the dance, integrate their understandings into the practical performance process, can show China's characteristic culture in the dance performance and give a unique artistic value to the dance performance [5]. Based on this, dance teachers should make students to integrate their own understandings and emotions into the dance performance so as to manifest the individualized style of dance performance, increase the artistic value of dance performance and also create conditions for the good inheritance and development of Chinese culture.

For instance, when learning the Spirit of Peacock, students need to not only learn the exquisite skills needed in the dance performance of Spirit of Peacock but also understand the Dai people's love toward peacocks and the upholding of peacock culture; thus, they can integrate the peculiar aesthetic tastes of Dai people and Dai nationality's rich national culture connation into the practical performance process, maximally manifest the quintessence of Chinese national culture and enhance the artistic charm of dance performance. Only in this way can Chinese culture be integrated into the national folk dance performance, the charm of Chinese culture be shown in national folk dances and the artistic values of Chinese national folk dances be further strengthened. In addition, when facilitating the good inheritance and development of Chinese national folk dances in modern society, it also creates favorable conditions for the inheritance and modernized development of Chinese culture and lays a solid foundation for the benign development of Chinese culture in the new era.

\section{Conclusion}

Chinese national folk dances contain rich connotations of Chinese culture. Only when the rich Chinese culture is permeated and shown in the dance performance, can the artistic values of Chinese national folk dances be really manifested to help Chinese national folk dances to be widely accepted by the masses. Therefore, educational practice of dance art, teachers should guide students to perfectly show Chinese culture in the national folk dance performance, thus, highlight the artistic values of national folk dances, help to better inherit and develop national folk dances in the new era and lay a solid foundation for the good inheritance of Chinese culture.

\section{References}

[1] Liu Shengchao. Permeation of Chinese National Culture in the National Folk Dance Teaching. Notonly Music, 2013(19):193-194.

[2] Li Yan. Brief Discussion on the Permeation of National Culture in Chinese National Folk Dance Teaching. Art Science and Technology, 2016,29(3):381-381.

[3] Wang Xinran. Brief Discussion on the Transmission of National Folk Dance Culture and Art. Literature Life (Trimonthly Publication), 2016(2):109-109.

[4] Xu Li. Brief Discussion on the Inheritance of National Folk Dance Culture. Journal of Hubei University of Economics (humanistic and social science), 2013(7):103-104. 
[5] Zhang Yu. Trial Discussion on the Transmission of Chinese National Folk Dance Culture and Art. North Music, 2013(12):107. 